\title{
Theoretical Basis for the Issue of the Influence of Cultural Values on the Intercultural Communication Development in Modern Society
}

\section{Lyalya Gainullovna Yusupova, Arzu Ismievna Sadygova1, and Mushfig Sadae- vich Agababaev²}

${ }^{1}$ Ural State Mining University, Yekaterinburg, Russian Federation

${ }^{2}$ Ural State University of Economics, Yekaterinburg, Russia

\section{Abstract}

This article considers the influence of cultural values on intercultural communication development in modern society. It focuses on the theoretical issues of intercultural communication and the degree of influence of cultural elements on its development. The authors note the interrelation between the modern system of intercultural communication development and the cultural model of society. The intercultural

Corresponding Author: Lyalya Gainullovna Yusupova lyalyax@bk.ru

Published: 21 January 2021

Publishing services provided by Knowledge E

(c) Lyalya Gainullovna Yusupova et al. This article is distributed under the terms of the Commons Attribution License, which permits unrestricted use and redistribution provided that the original author and source are credited.

Selection and Peer-review under the responsibility of the XXIII International Conference Conference Committee.

\section{S OPEN ACCESS} communication development implies a close "interaction of cultures" and communication among different nations. According to the authors, the intercultural context identifies the concepts of "interaction" and "communication". The problem under discussion is of importance due to the identification of the degree to which culture influences the modern system of intercultural communication development. The article considers the mechanism of the influence of cultural values of individual nations on the development of intercultural communication of a person and the ways of its reflection in modern society. Based on the studies of researchers such as A.P. Sadokhina, T.G. Grushevitskaya [8], Wilhelm von Humboldt [9] and others, the article describes various levels of influence of cultural values on the interrelation of nations. The authors deal with the problems of interaction, borrowing, understanding, perception of cultural values characteristic of a certain nation and those attributed to other ones, as well as intercultural conflicts and their solution, phenomena of ethnocentrism and cultural diffusion in the process of intercultural communication development in modern society. The authors number the problems of affective reaction and adaptation among the main problems of intercultural communication development in modern society. They also raise a current issue of cultural globalization and the idea of global culture. The article aims at identifying the degree to which cultural values influence the intercultural communication development in modern society. In order to achieve the aim, the authors set the following tasks: - to analyze the theoretical issues of the influence of cultural values on the intercultural communication development; - to identify the particular features of the influence of cultural values on the intercultural communication development. The interaction between a language and culture of a certain nation is considered as an essential component of the intercultural communication development. The authors accept the view that the linguistic system and cultural values are the main carriers of information about history, traditions, religion 
and other spheres of the people's existence. The authors emphasize the mandatory participation of a language and culture in the intercultural communication development. In conclusion, using the formula, the authors confirm the theory of the influence of cultural values on the intercultural communication development in modern society.

Keywords: communication, development, culture, modern society, individual.

\section{Introduction}

The article accentuates a noticeable difference in the behavior of certain groups of people, which results from the difference in their cultural identity. Along with its distinctive function, culture has the ability to unite both individuals and entire nations. It should be noted that unification occurs through the interaction and "dialogue of cultures". Certain cultures cannot exist in isolation. Centuries-old knowledge and experience of people belonging to different nations can change and come down from one culture to another, thus uniting different groups of people.

Cultural interaction occurs through communication, which is commonly called "intercultural communication." In modern society, the need for the development of intercultural communication has noticeably grown due to the increase in social and economic relations. At the same time, there has emerged a necessity to develop intercultural communicative competence of specialists in various industries and willingness of society members to interact with different cultures.

The concept of 'culture' is evaluative in its nature and reflects personal qualities of an individual. In addition, it reflects human behavior, a combination of traditions and customs. The versatility of this concept makes it possible to reflect the human nature throughout history of its existence. Culture is an evolving system that involves communication and interaction.

However, existing differences among cultures may be obstacles to intercultural communication in modern society. To overcome such obstacles, it is necessary to have knowledge and skills of communication with representatives of other cultures, which is the main goal of intercultural communication development.

The works of N.A. Berdyaev, N.Z. Chavchavadze, M. Weber [1], and others, emphasizing the social nature of culture, deal with the issues of interrelation of culture and intercultural communication. V.S. Stepin studies the problem of cultural development 
under the influence of communication. The works of M.M. Bakhtin, A.F. Losev, Yu.M. Lotman [7] consider the relation between the theoretical problems of communication and the definition of the concept of 'dialogue'. The role of the language system in culture and communication is studied by V.I. Gulyaev and V. Humboldt [9]. M.M. Bakhtin, V.S. Bibler [3], and others emphasize the communicative role of art and culture. The importance of cultural values in society is the main focus in the works of B. Malinovsky, T. Parsons, M. Weber and others [12].

In modern society, each person is a member of a particular sociocultural group with its own microculture. Having different religious beliefs, geographical origin, language, and education, members within a sociocultural group have common interests and goals. The ability to find common ground and not focus on differences is the main priority of intercultural communication development.

\section{Methodology and Methods}

The information we receive is considered from the perspective of our own culture. The experience and knowledge passed down from generation to generation form our culture of perception, behavior and create a category of values playing an important role in every person's life. The values influence the way a person receives the information in the process of communication, builds relationships in society, expresses his feelings and emotions, interacts etc. According to A. Sadokhin, value is not an object but the expression of our attitude to things, events and phenomena. The role of values in peoples' culture is great; they determine the interaction of people with nature, society, relatives and themselves [8].

Each culture has different norms, customs and traditions which form a system of values in the minds of people. Being a life guiding star of a person, the value system can change, enlarge, and be different for different sexes and groups of people, while remaining identical and unique.

In modern society, the cultural values comprise artistic values of the world as well as customs, morals, and traditions of certain nations. In the process of intercultural communication development, it is necessary to take into account the peculiarities of values perception by members of different cultures. There is a concept of the universal human values reflecting common beliefs in everyday life, art and religion of different nations. Everyday (ethnic) values that people encounter in everyday life play a significant role in the development of intercultural communication. The values of everyday culture are fundamental in the formation of an individual and significant for his attitude to other 
groups of values. Guided by these cultural values, an individual gets involved in an intercultural communicative act and hopes to be understood by the members of other cultures. Thanks to the assimilated values of his own everyday culture, an individual can perceive and understand other cultural values. Understanding of art and religion results from the understanding of the values of everyday culture. It is important that cultural values unite groups of people, form a sense of community and develop communication skills in modern society.

An individual learns the importance of values through the comparative paradigm of the values characteristic of his own culture and those attributed to other ones. This process is facilitated by the dialogue of cultures and intercultural communication. An adequate perception of the cultural experiences of all the participants involved in an intercultural communication act eliminates misunderstanding of the partners.

Cultural values have the norms which comply with generally accepted rules and have an impact on all spheres of human life, including intercultural communication. The emergence of cultural values runs parallel to the formation of the norms of behavior and interaction (communication) which are based on the customs and traditions of different nations. The evaluation of an individual's moral behavior is based on moral standards. The development of intercultural communication in modern society requires the formation of moral standards on the basis of cultural values. The identification of common norms of behavior, similar traditions and customs of the participants involved in a communicative act contributes to the development of modern intercultural communication.

The success of intercultural communication in modern society depends on its participants' adequate perception of one another. Adequate perception is formed under the influence of culture, education, upbringing, life experience and many other factors. The importance of cultural environment in the formation and development of adequate perception in the course of intercultural communication cannot be overestimated. An individual's cultural identity has an effect on his interaction with other people. In intercultural communication, the parties are guided by evaluative information perception formed by the cultural view of the world.

In intercultural communication people perceive ethnic cultural values of other nations comparing them with their own values. In scientific literature this process is called "ethnocentrism". In ethnocentrism, other cultures are viewed as inferior to the native one which is believed to be the norm. As has already been noted, other cultural values are perceived through the paradigm of native culture. Ethnocentrism goes back to antiquity when everything that was "alien" was considered to be strange and bad. 
Ethnocentrism characteristic of all cultures also influences the development of intercultural communication in modern society. Interacting with other cultures, parties compare them with those they belong to. This interaction often leads to the conflicts, and their solution depends on the perception of the participants involved in intercultural communication. The conflicts are the result of the opposition or comparison of native and alien cultures. Awareness of cultural values allows an individual to solve a communicative conflict, to choose an effective method of interpreting the phenomena of another culture and to achieve a positive result in modern intercultural communication.

The role of ethnocentrism in the development of intercultural communication in modern society is assessed differently. According to some researchers, ethnocentrism gives rise to nationalism, and it is an obstacle to the development of intercultural communication. Meanwhile, there is an opinion that it is indispensable for preserving the identity of different cultures. The influence of ethnocentrism depends on the degree of its manifestation and social environment.

In modern society, the intercultural communication development results in the shift of cultural elements of different nations, which is clearly reflected in the youth subculture, which prefers similar music, clothing, behavior, etc. At the same time, the older generation tries to maintain the originality of their native culture. In intercultural communication, this phenomenon is called "cultural identity." It expresses an individual's awareness of his belonging to a particular culture, defines preferences, habits, tastes, cultural values, etc. Being involved in intercultural communication, people act in accordance with their own cultural norms and cultural identity.

The intercultural communication development involves communication and interaction of representatives of different cultures. The effectiveness of intercultural communication largely depends on the cultural elements that make up the cultural system. Actions, thoughts, behavior, language of an individual reflect his cultural identity, and they should be evaluated by the representatives of other cultures in accordance with his cultural norms. The basis of this perception is the recognition of the equality of the 'native' and 'foreign' cultural values. In modern society, cultural equality plays a significant role in the development of intercultural communication, implying a tolerant attitude to other cultural values and norms.

Due to the mechanism and dynamics of their constant development, the world cultures change, thus bringing about innovations, products of cultural experiences and their borrowings. The latter ones often result from the development of intercultural communication and depend on its effectiveness. Conditions, degree and intensity of the intercultural communication development also influence cultural borrowings. In the 
process of intercultural communication development, the interaction of cultural elements and their synthesis may result in the emergence of completely new phenomena. Cultural partnership and synthesis are widely used in Japan and East Asian countries.

It is difficult to imagine modern intercultural communication without cultural diffusion, when the interaction of different cultures leads to the interpenetration of individual elements that make up the cultures of different nations. Cultural diffusion, or borrowing, is an effective way of cultural and national development. It has an impact on the existence of cultures and nations through the diffusion of innovations. The process of borrowing may occur as a result of trade and tourist relations, migrations, scientific conferences, etc. The exchange of cultural values or their transmission from one culture to another is especially important in the process of modern intercultural communication development. It should be noted that cultural diffusion is a mixed blessing. On the one hand, close communication of nations and borrowing of cultural values contribute to their development and bring them closer while, on the other hand, cultural diffusion may lead to a loss of cultural identity.

In modern intercultural communication, the issue of cultural globalization, which occurs as a result of the expansion of cultural boundaries, is also of great importance. Developing tools of communication, economic ties and transport links with different countries are direct manifestations of cultural globalization. In intercultural communication it is reflected in the development of intercultural ties and interrelation of cultural elements. The process of cultural globalization in modern society has an impact not only on the whole cultures but also on their bearers, blurring the boundaries between native and foreign cultures.

Modern society has to solve global problems connected with world economy, politics, culture, ecology and human survival. It often raises an idea of creating a unified world (global) culture, which may greatly affect the existence of all mankind.

The studies of modern anthropologists note the interrelation and interdependence of all changes in culture, the compliance of all the cultures with the general laws of communication. They emphasize the common features in the development of intercultural communication and world culture such as the development of skills and abilities to perceive a foreign culture, the analysis of behavior from the perspective of a native culture, and the ability to get involved in intercultural dialogue. Cultural changes often submit to the rules of intercultural communication and have a tendency to intercultural cooperation. An individual should enrich his native culture, preserving the elements of his own culture and borrowing the values of other cultures. 
Culture and communication run in parallel with each other, and their interrelation is studied by various fields of science, such as psychology, philosophy, cultural studies, sociology, linguistics, etc. Communication is viewed as a social process of information exchange by means of various communication tools whereas culture represents a characteristic of human interaction with other people and the world. Everything created by mankind is its culture, including communication. Some scholars identify culture and communication. E. Hall calls culture communication, and vice versa. A person forms, perceives the world, and gains experience through communication (interaction). Each type of culture has its own way of communication. Scientific literature distinguishes such levels of communication as communicative, interactive, and perceptual. The communicative level involves communication through language and cultural traditions.

Communication reflects interaction, interconnection and information exchange among people. Being multi-functional, communication can have several aspects, among which informativity is of first priority. The formation and development of skills of successful social and cultural activities of an individual, the exchange of information and experience, the shaping of a person's behavior are the main goals of communication in modern society.

Intercultural communication is of particular importance among political, informational, professional, interpersonal, and other types of communication. An intercultural communicative act can occur verbally and non-verbally. A human is the only subject of communication, whose development requires interrelation with other people and cultures. The effectiveness of the relationships depends on the personal culture of the participants involved in the communicative act.

Throughout the existence of mankind, an individual has tried to understand peculiarities of other cultures and their bearers, to compare his native culture with a foreign one. The history of the concept of "intercultural communication" dates back to 1954, when G. Treiger and E. Hall wrote a book "Culture as communication. Model and analysis". In it, intercultural communication is viewed as the main goal of a human in his attempt to understand and accept the world around him. According to the authors, the main condition for intercultural communication is the mandatory belonging of its participants to different cultures. Any communication (interaction) of representatives of different cultures is considered to be intercultural communication. Bearers of different cultures perceive information in different ways because of different levels of their preparedness for intercultural communication.

Participants of intercultural communication are bearers of their native culture, and the effectiveness of communication depends on their profession, age, social status, 
personal experience, their own cultural values, and individual tolerance [8]. Sadokhin A.P. describes intercultural communication as a combination of various forms of communication and relations among individuals and entire groups of representatives of different cultures. Depending on its scale, modern intercultural communication can have various levels which include communication of social groups, countercultural communication, interethnic communication, communication of rural and urban residents, regional communication, etc. The only thing all these levels of intercultural communication have in common is the fact that the participants involved in a communicative act recognize their own culture, behavior and lifestyle as true ones and have inadequate perception of other cultures. Communication of different cultures implies the contact of different worldviews, but participants involved in an intercultural communicative act do not perceive the obvious differences of cultures. There is an algorithm to recognize the difference and equality of 'native' and 'foreign' cultures. The main objective of intercultural communication development in modern society is the formation of communication skills and tolerant perception of the elements of other cultures and their bearers.

Interaction with other cultures may cause fear, anxiety and psychological stress, which leads to an affective reaction. To determine the level of complexity of intercultural communication and the degree of affective reaction to a 'foreign' culture, anthropologists introduced the concept of "cultural distance", which allows us to identify the degree of compatibility of different cultures. It is known that cultures with a shorter cultural distance are easier to adapt because the elements of these cultures are less different. The proximity and similarity in lifestyles, religion, traditions, language, clothing, and climatic conditions contribute to the convergence of cultures and simplify the process of intercultural communication development.

Besides, modern intercultural communication pays special attention to the process of adaptation, which reflects the dynamics of gradual adjustment (adaptation) of an individual to a 'foreign' culture. The dynamics of adaptation depends on a number of factors such as positive attitude to communication, motivation, participation in social activities, language skills, etc. It should be noted that it is impossible to gain full understanding in the process of intercultural communication, and that the success of such interaction depends on the context.

Speaking about the influence of culture on the development of intercultural communication in modern society, it is necessary to note the role of a language in the process of communication (interaction). The existence of world cultures and the development of intercultural communication are impossible without a language system. Language, as the main unit of a language system, is a means of communication (interaction). It 
is often called a mirror, a pantry, a tool and a culture bearer reflecting the character of a nation, its cultural values and traditions, history and everyday life. According to Wilhelm von Humboldt's theory of linguistics, all linguistic differences of the nations are interconnected and "mental strength of a human" has a great influence of them [9]. S.G. Ter-Minasova, a specialist in the field of intercultural communication, notes the role of a language in the formation of culture and calls it a treasury and a piggy bank that stores cultural values at different levels of the language system [14].

Language is closely connected with the 'national spirit' and cultural values. All historical and cultural changes in the life of the people are reflected in the language. As a language reflects a communicative process, it becomes obvious that it is closely connected with culture and communication and cannot exist without them. Being one of the main components of culture and communication, language serves their development.

The intercultural communication development in modern society runs parallel to the formation of an individual's world perception, which proceeds under the influence of cultural and natural (social) environment. The formation of perception depends on the level of personality development. Being involved in intercultural communication with representatives of other cultures, a person encounters the way of talking, behavior, sounds and gestures which are not typical for his native culture. In the process of intercultural communication, the perception of the manifestation of the cultural elements characteristic of other participants involved in a communicative act depends on an individual's cultural identity. Thus, an individual's own culture controls his perception of the information received. An adequate perception of a 'foreign' culture results in understanding and adaptation.

In conclusion, taking into account all of the above, we have worked out a formula for interrelation of cultural values and intercultural communication development, where $C$ is the world culture, $C 1$ is the national culture, $C 2$ is the personal culture, IC is the intercultural communication.

$$
C 1+C 2=C+I C
$$

It should be noted that the influence of culture on the development of intercultural communication in modern society is a complex, multifaceted and lengthy process. The cultural characteristics of every nation have an impact on all spheres of life, including the development of intercultural communication, which is achieved through personal and social communication. The interrelation of cognitive, behavioral and affective aspects forms the basis for intercultural communication (interaction) in modern society. The development of intercultural communication and accumulation of knowledge about a 
foreign culture contribute to better understanding of the world. Perceiving a 'foreign' culture, an individual must be able to express his feelings in the context of this culture. At the same time, he acquires behavioral skills in accordance with the new social conditions. In modern society, culture influences the development of intercultural communication, promotes the development of intercultural relationships, provides an individual with an analytical and critical view of 'native' and 'foreign' culture, and forms a special way of thinking and a view of the world.

\section{References}

[1] Abisheva, A. K. (2002). About the Concept of Value. Problems of philosophy, vol. 3, pp. 139-146.

[2] Arutyunov, S. A. and Cheboksarov, A. N. (1972). Information Transmission as a Mechanism for the Existence of Ethnosocial and Biological Groups of Mankind. Races and Nations, vol. 2, pp. 27-59.

[3] Bibler, B. C. (1989). Culture. Dialogue of cultures. Problems of Philosophy, vol. 6, pp. 31-43.

[4] Vereshchagin, E. M. and Kostomarov, V. G. (1990). Language and Culture. Moscow: Russkiy Yazyk, p. 246.

[5] Vasilenko, L. I. and Ermolaeva, V. E. (1990). Global Problems and Universal Values. Moscow: Progress, p. 495.

[6] Goiko, E. V. (2011). Barriers to Intercultural Communication. Bulletin of MSUCA, vol. 2, pp. 47-51.

[7] Greidina, N. L. (2004). On the Problem of Implementation of the Cultural-Linguistic Policy. Problems of Communication and Culture. Pyatigorsk: PSLU.

[8] Grushevitskaya, T. G., Popkov, V. D. and Sadokhin, A. P. (2003). Fundamentals of Intercultural Communication: Textbook for Universities. Moscow: UNITY-DANA, p. 352.

[9] Humboldt, V. (1984). Language and Philosophy of Culture. Moscow: Progress, p. 448.

[10] Zilberman, D. B. (1995). Tradition as Communication: Transmission of Cultural Values, Writing. Problems of Philosophy, vol. 4, pp. 76-105.

[11] Cassidy, F. K. (2003). Globalization and Cultural Identity. Problems of Philosophy, vol. 1, pp. 76-79.

[12] Leontyev, D. A. (1996). Value as an Interdisciplinary Concept, the Experience of Multidimensional Construction. Problems of Philosophy, vol. 4, pp. 15-26. 
[13] Prazdnikov, G. A. (1981). Tradition as a Dialogue of Cultures. Soviet ethnography, vol. 3, pp. 54-56.

[14] Ter-Minasova, S. G. (2000). Language and Intercultural Communication. Moscow: Slovo, p. 624

[15] Filimonov, S. L. (2000). Symbol and its Role in Communication. Philosophy and society, vol. 4, pp. 154-158.

[16] Khaleeva, I. I. (2000). On Gender Approaches to the Theory of Teaching Languages and Cultures. Bulletin RAE, vol. 1., pp.278 - 303

[17] Shreider, Y. A. (1993). Communication Culture in Informatization Environment. Problems of Information Exchange, p. 353

[18] Shreider, Y. A. (1999). Values We Choose. Meaning and Factors Influencing the Choice of Values. Moscow: Editorial URSS, p. 208.

[19] Yusupova, L. G. and Tulupova, O. V. (2008). Intercultural Communication as a Form of Interaction of the Representatives of Different Cultures. Innovative Processes in the System of University Education: Social and Humanitarian Aspect. Presented at Proceedings of the International Scientific and Methodological Conference. MSTU, Magnitogorsk, Publishing House of Magnitogorsk state technical University, pp. 8992. 